Reading and listening comprehension and their relation to inattention and hyperactivity

\author{
Kate Cain \\ Lancaster University \\ Simon Bignell \\ University of Derby
}

Correspondence to: k.cain@lancaster.ac.uk

To be published in British Journal of Educational Psychology

DOI: 10.1111/bjep.12009 
Abstract

Background: Children with diagnoses of ADHD frequently have reading problems. To date, it is not clear whether poor reading is associated with both inattention and hyperactivity and also whether poor reading comprehension is the result of poor word reading skills or more general language comprehension weaknesses.

Aims: We report two studies to examine how reading and listening comprehension skills are related to inattention and hyperactivity/impulsivity.

Samples: Separate groups of 7- to 11-year-olds participated in each study.

Methods: In both studies we used teacher ratings of inattention and hyperactivity/impulsivity to identify three groups at-risk of ADHD: poor attention, high hyperactivity, poor attention and high hyperactivity, and also same-age controls. In Study 1 we explored how inattention and hyperactivity predicted reading after controlling for nonverbal IQ and vocabulary. In Study 2, we compared listening and reading comprehension in these groups.

Results: Poor attention was related to poor reading comprehension, although the relation was partially mediated by word reading skill (Study 1). Groups with high hyperactivity had weak listening comprehension relative to reading comprehension (Study 2).

Conclusions: These results indicate that the reading comprehension problems of children with attention difficulties are related to poor word reading, and that listening comprehension is particularly vulnerable in children at risk of ADHD.

Keywords: inattention, hyperactivity, reading comprehension, listening comprehension, word reading, school-aged children 


\section{Reading and listening comprehension and their relation to inattention and hyperactivity} Attention-Deficit/Hyperactivity Disorder (ADHD) is a developmental disorder with two behavioural symptoms: poor attention and impulsivity/hyperactivity (DSM-IV: American Psychiatric Association(Association), 1994). These symptoms may occur together or separately, resulting in three recognised subtypes: predominantly inattentive, predominantly hyperactive-impulsive, and combined type. ADHD is estimated to affect $2-5 \%$ of children in the UK and is more commonly diagnosed in boys than girls (Carroll, Maughan, Goodman, \& Meltzer, 2005).

Children with ADHD commonly experience academic problems, notably reading difficulties (Bauermeister et al., 2005; Carroll, et al., 2005; Frazier, Youngstrom, Glutting, \& Watkins, 2007; Hinshaw, 1992; Shaywitz, Fletcher, \& Shaywitz, 1995). When considering the two symptoms separately, some research indicates a specific relation between inattention and poor reading (Willcutt \& Pennington, 2000), whilst other work finds that hyperactivity is related to reading difficulties (Adams \& Snowling, 2001; McGee, Prior, Williams, Smart, \& Sanson, 2002; McGee, Williams, Share, Anderson, \& Silva, 1986). There are few studies that have compared two or more subtypes. Those that have done so support the link between inattention and reading problems. The inattentive and combined subtypes perform more poorly on reading assessments than controls (Bauermeister, et al., 2005; Lamminmäki, Ahonen, Närhi, Lyytinen, \& de Barra, 1995), whereas children with only symptoms of hyperactivity do not (Lamminmäki, et al., 1995). Further, improvements in attention are associated with gains in reading scores (Aro, Ahonen, Tolvanen, Lyytinen, \& Todd de Barra, 1999). Thus, although limited, research to date indicates that children with attention 
problems are more likely to experience reading difficulties than those with hyperactivity in the absence of inattention.

Our understanding of both the nature and the extent of the link between the symptoms of ADHD and reading are limited because most previous research has not considered word reading and reading comprehension separately. It is well established that reading comprehension difficulties can arise for different reasons: because of a bottleneck in language processing caused by poor word reading (Perfetti, 1985), or in the presence of age-appropriate word reading, because of weak semantic (Nation \& Snowling, 2004) or discourse-processing skills (Cain \& Oakhill, 2006). These two sources of poor reading comprehension are captured in the Simple View of Reading (Gough \& Tunmer, 1986), the framework for literacy instruction in the UK. Although reading comprehension is dependent on the ability to read words accurately and fluently, reading comprehension and word reading are separable aspects of literacy, which can develop or fail to develop independently of one another and are determined by different language and cognitive skills (de Jong \& van der Leij, 2002; Kendeou, Savage, \& van den Broek, 2009; Muter, Hulme, Snowling, \& Stevenson, 2004; Oakhill \& Cain, 2012; Oakhill, Cain, \& Bryant, 2003). When considering reading problems, it is therefore important to examine performance of both word reading and reading comprehension to distinguish between children whose difficulties arise at the word reading level, discourse comprehension level, or both. The two sources of comprehension difficulty will require fundamentally different types of support in the classroom.

There are only a handful of studies of children with ADHD that have included separate assessments of word reading and reading comprehension. This work has typically 
measured the accuracy of word reading, rather than fluency, and an inconsistent pattern of findings is evident. One study reports a pattern of poor word reading but non-impaired reading comprehension (Bental \& Tirosh, 2007), whilst another reports the reverse pattern (Brock \& Knapp, 1996). Two others found that children with ADHD had both poorer word reading and poorer reading comprehension than controls (Lombardino, Riccio, Hynd, \& Pinheiro, 1997; Willcutt, Pennington, Olson, Chhabildas, \& Hulslander, 2005). Thus, the weight of evidence to date indicates that children with ADHD have weaker reading comprehension than peers. It should be noted, however, that the children diagnosed with ADHD in the latter two studies obtained standardised scores in the average range (95-105). Thus, although their reading scores were lower than those obtained by controls, they were not substantially impaired.

Clearly, children with ADHD are likely to have poorer reading comprehension than peers, but studies to date have not controlled for word reading level making it hard to draw firm conclusions about the likely basis of reading comprehension weaknesses. As noted above, poor reading comprehension may be the result of poor word reading. However, good understanding of a text requires the strategic allocation of attention, as well as the planning and information processing behaviours that are often impaired in children with ADHD (Pennington \& Ozonoff, 1996). Thus, it is plausible that children with ADHD may experience reading comprehension problems that are independent of any difficulties with word reading, because of their poor attention and/or executive skill weaknesses. In support of this proposal, there is strong evidence of poor listening comprehension in children with ADHD (Lorch et al., 1999; McInnes, Humphries, Hogg-Johnson, \& Tannock, 2003) and 
reading and listening comprehension draw on many of the same language and cognitive skills (Hoover \& Gough, 1990).

The method used to assess reading comprehension may also influence performance and provide clues to the source of difficulty on these tasks. One way to determine whether or not reading comprehension difficulties arise because of poor word reading is to compare comprehension in two presentation modalities: written vs. spoken text. If comprehension is weak only for text that the individual has to read (relative to some standard score or control group), we can infer that weak word reading skills are a likely source of the reading comprehension problem; if comprehension is weak in both presentation modalities, we can infer that the individual has a general comprehension deficit (Keenan, Betjemann, Wadsworth, DeFries, \& Olson, 2006).

However, written and spoken text may differ not only with regard to whether a visual stimulus has to be decoded or not, but also in the cognitive processing demands and support that each type of modality entails. It has also been suggested that if poor comprehension is related to an inability to focus or sustain attention when following a text, children with ADHD may be more severely impaired on comprehension tasks that have greater attention demands, that is children with ADHD may be particularly vulnerable on measures of listening comprehension relative to measures of reading comprehension (Aaron, Joshi, Palmer, Smith, \& Kirby, 2002). In addition, reading may have an advantage over listening comprehension because the comprehender can control the pace of delivery of information (Aaron, et al., 2002; Perfetti, 1985). Visually presented text may help the reader to focus attention and minimise distractibility, because each word needs to be decoded. There are no direct empirical questions of this proposal to date, but the task of reading 
aloud has been shown to benefit groups diagnosed with ADHD (Ghelani, Sidhu, Jain, \& Tannock, 2004).

Successful comprehension enables learning, thus both reading and listening comprehension are crucial for learning and academic achievement (Kintsch, 1998). The relatively common incidence of ADHD, the extent of the academic problems experienced by this population, and the lack of clarity about their reading difficulties outlined earlier, highlight the need for further examination of reading and listening comprehension in relation to the symptoms of ADHD. Specifically, it is not clear whether reading comprehension difficulties when they do arise are the result of comorbid word reading difficulties or the attention and/or executive skills deficits experienced by this population. Thus it is not clear whether this population experiences general language comprehension difficulties, or difficulties related to the reading process.

To address these concerns, we examined the reading and listening comprehension of children at risk of ADHD in relation to typically developing controls. In Study 1 we examined the extent to which the symptoms of ADHD (inattention and hyperactivity) predicted reading comprehension whilst controlling for word reading; in Study 2 we compared the reading and listening comprehension of groups who showed the characteristics of ADHD subtypes with controls (same-age peers who did not have symptoms of inattention or hyperactivity). ADHD is often comorbid with oral language problems (Tirosh \& Cohen, 1998) making it hard to interpret any association between attention, hyperactivity, and reading/listening comprehension. For that reason, we used a similar logic to Bental and Tirosh (2007) and controlled for oral receptive vocabulary in this research. Because we were interested in group differences associated with language comprehension, rather than 
general ability, we also controlled for nonverbal ability in both studies. We did not include children diagnosed with ADHD. Instead, we obtained teacher ratings to select children at risk of ADHD with profiles similar to the ADHD subtypes and compared their performance with typically developing controls, a method previously used to explore language and attention deficits in relation to the symptoms of ADHD (Adams \& Snowling, 2001; Bignell \& Cain, 2007; Wilding, Munir, \& Cornish, 2001).

Our predictions were as follows. If the reading comprehension difficulties associated with the symptoms of ADHD arise because of word reading difficulties, the relation between these symptoms and performance on measures of reading comprehension should be reduced when word reading ability is controlled (Study 1). If comprehension difficulties arise because of weak attention/executive skills, performance should be best when the task is less compromised by fluctuations in attention. Thus reading comprehension should show an advantage over listening comprehension (Study 2).

\section{Study 1}

The aim was to determine whether or not reading comprehension was directly associated with teacher ratings of attention and/or hyperactivity, or mediated by word reading level.

\section{Method}

\section{Participants}

Sixty-six children ( 44 male, 22 female) aged 7 to 11 years participated in this study. All attended mainstream suburban primary schools serving middle and lower-middle class catchment areas in the East of England. Children were excluded whose first language at home was not English, who had a diagnosis of a hearing, speech, or language disorder, a 
formal statement of special educational needs, or for whom parental consent was not given. None of the children were receiving medication to treat ADHD.

\section{Assessments and selection procedure}

Inattention and hyperactivity. Teachers of children $(\mathrm{N}=300)$ aged 7-11 years completed the two subscales of the ADD-H Comprehensive Teacher Rating Scale (ACTeRS: Ullmann, Sleator, \& Sprague, 1999) relating to attention and hyperactive behaviour. Ratings are made on a five-point scale from 'almost never' through to 'almost always' in response to statements about the observed behaviour of an individual child compared with his or her classmates. The hyperactivity subscale has five questions ( 5 - 25 range) and the attention subscale has six questions (6 - 30 range). The reliabilities of the two subscales are high: .93.97. We selected children who fit the profile of the three recognised subtypes of ADHD (poor attention only, high hyperactivity, combined type). Thus, they either had very poor attention (scores between 20-30), very high hyperactivity (scores between 16-25), or poor attention and high hyperactivity. For each child, a peer (matched for chronological age and gender) was selected who obtained developmentally appropriate scores (inattention scores between 6-9 and hyperactivity scores between 5-8) on both (see Wilding, Munir, \& Cornish, 2001, for similar cut-offs). For the values reported throughout, the attention scale has been reversed thus, for each scale, high scores indicate a tendency towards inattention or hyperactivity. There were 11 children in each group. Group characteristics and matching statistics are reported in Table 1.

\section{INSERT TABLE 1 AROUND HERE}

For validity, teachers were asked to complete the short form of the Conners' Rating Scales-Revised (CRS-R: Conners, 1997) and these were returned for 56 of the children. The 
CRS-R teacher inattention ratings were highly correlated with the ACTeRS' attention ratings, $r=.90, p<.001$, and the two hyperactivity ratings were also highly correlated, $r=.93, p<.001$. Parent ratings on the CRS-R scales were available for 34 children. These also correlated highly with the teacher ACTeRS' ratings, $r=.79, p<.001$ for attention and $r=.66, p<.001$ for hyperactivity, and with the teacher CRS-R ratings, $r=.76, p<.001$ for attention and $r=.63, p<$ .001 for hyperactivity. None of the children in the control groups obtained scores above the thresholds for either inattention or hyperactivity on either form. For the children at-risk who matched the profile for one of the three ADHD subtypes, the majority (between 55 $82 \%$ of returns) met the thresholds for the appropriate symptom (dependent on subtype).

Vocabulary. Receptive vocabulary was measured with the British Picture Vocabulary Scale - II (BPVS-II: Dunn, Dunn, Whetton, \& Burley, 1997). In this assessment, children are shown four pictures and have to select the picture that represents a word spoken by the assessor.

Non-verbal ability. Non-verbal reasoning ability was assessed with the Matrix Analogies Test - Short Form (MAT-SF: Naglieri, 1985).

Word reading accuracy and reading comprehension. All children completed the Neale Analysis of Reading Ability - Revised British Edition (Form 1) (NARA-II: Neale, 1997). In this assessment, children read aloud short passages and answer a set of comprehension questions after each one. Testing stops once a prescribed number of word reading errors have been made on a given story. The number of word reading errors (collated over stories) is used to determine a score for word reading accuracy in context and the number of comprehension questions answered correctly is used to determine a reading comprehension score. 


\section{Results and summary}

The performance on the measures of non-verbal ability, vocabulary, and reading are reported in Table 2. Standardised scores (for which average performance for a given chronological age is 100) are reported for the BPVS and NARA-II, and stanine scores (for which average performance for a given chronological age is 5) for the MAT-SF. The hyperactive-only at-risk group did not differ from controls on any measure. In contrast, the inattention-only at-risk group differed significantly from controls on receptive vocabulary and both the inattention-only and the combined at-risk groups differed from controls on the measures of word reading and reading comprehension. As the standardised scores in Table 2 indicate, these two groups had weak reading skills. The combined group obtained word reading accuracy and reading comprehension scores that were more than one standard deviation below the population mean $(<85)$; the poor attention group obtained a low word reading accuracy score although it was within one standard deviation of the population mean (88.09) and their reading comprehension score was below the population mean $(<85)$.

\section{INSERT TABLE 2 AROUND HERE}

The correlations (non-parametric because the attention and hyperactivity ratings were not continuous) between variables are reported in Table 3 using standardised/stanine scores where available to control for age. In line with the group data reported in Table 2, hyperactivity ratings did not correlate significantly with any variables other than inattention; in contrast, inattention ratings correlated significantly with vocabulary, word reading accuracy, and reading comprehension. Further, non-verbal ability was weakly related with vocabulary and the two measures of reading, which were strongly correlated. 
Our aim was to determine whether attention and hyperactivity ratings made unique contributions to reading performance. Because hyperactivity was not correlated with our reading measures, we did not analyse it further. In the light of the relations between nonverbal ability, vocabulary, and reading it was necessary to control for the influence of the first two variables. ANCOVA is not appropriate when the independent variable and covariates are not independent (Miller \& Chapman, 2001). Therefore, to investigate this aim we conducted two pairs of fixed-order multiple regression analyses. In one analysis word reading accuracy was the criterion and in the other reading comprehension was the criterion. Because the attention data were not normally distributed, the rating scale was coded as a dichotomous variable using the cut-off values reported in the Method. Standardised scores and stanines were used for the other measures, as available.

\section{INSERT TABLE 4 AROUND HERE}

The results of these two main regression analyses are reported in the first two sections of Table 4. In both, nonverbal ability (MAT-SF), and receptive vocabulary (BPVS-II) were entered in the first step as control variables. They predicted unique variance in both word reading accuracy and reading comprehension. In the final step, attention grouping (poor, good) was entered and found to explain additional variance in the prediction of word reading accuracy and also reading comprehension.

We conducted a third set of multiple regression analyses to test our prediction that the relation between attention and reading comprehension may be mediated by word reading ability. In these analyses, the contributions made by vocabulary and nonverbal IQ were controlled and then word reading and attention were entered in the second and third steps to predict reading comprehension. The results of these analyses are summarized in 
Table 4. They show that word reading and attention ratings each explain unique variance in reading comprehension, when entered in the final step. Using Baron and Kenny's 1986) criteria we found evidence that word reading was a partial mediator of the relation between attention ratings and reading comprehension: attention ratings accounted for significant variance in reading comprehension $(B=-10.51$, S.E. $=2.12, t=-4.95, p<.001)$ and also in word reading $(B=-12.76, S . E .=2.30, t=-5.54, p<.001)$, and word reading accounted for significant variability in reading comprehension when controlling for attention $(B=.35$, S.E. $=.10, t=3.22, \mathrm{p}<.01)$. Critically, the effect of attention ratings on reading comprehension was reduced when entered simultaneously with word reading $(B=6.03$, S.E. $=2.42, t=-.249$, $p=.015)$.

To test for the statistical significance of mediation, we followed the recommendations of Preacher and Hayes (2008) and conducted bootstrapped tests for the indirect (mediated) effect, based on 1000 bootstrap samples. A point estimate for the indirect effect (of inattention via word reading) was considered statistically significant if zero was not included in the $99 \%$ bias-corrected confidence intervals, which is what we found $(\mathrm{PE}=-4.48, \mathrm{BC} 99 \% \mathrm{Cl}$ of -10.61 to -1.05$)$. Finally, the difference between the standardized beta coefficients for word reading $(B=.410)$ and inattention $(b=-.281)$ in the final regression equation predicting reading comprehension was statistically significant $(p<$ .01 , see Cohen \& Cohen, 1983).

Together our analyses demonstrate that both attention and word reading ability are related to children's reading comprehension level. Two sources of evidence suggest that word reading level was the stronger determiner of reading comprehension scores. First, there was evidence that word reading was a statistically significant partial mediator of the 
relationship between inattention and reading comprehension in this sample. Second, the standardized beta weights show that word reading made a greater contribution than did attention ratings to reading comprehension outcomes.

\section{Study 2}

This study tested the hypothesis that the additional demands of a listening comprehension task might adversely affect performance in children with symptoms of inattention and/or hyperactivity, as outlined in the Introduction. To do this, we compared reading and listening comprehension performance between at-risk subtypes (attention only, hyperactivity only, combined type) and controls who were matched for chronological age, nonverbal ability and vocabulary. This careful matching allowed us to look at the separate and combined contributions of the symptoms of ADHD. In addition, measures of single word reading and word reading in context were taken to relate to reading comprehension performance.

\section{Method}

\section{Participants}

Sixty-four children (different to those who participated in Study 1) participated and were selected using the same procedures outlined for Study 1. Group were matched for chronological age, non-verbal ability and, different to Study 1, receptive vocabulary (see Table 5). None of the children were receiving medication to treat ADHD.

\section{TABLE 5 AROUND HERE}

\section{Group selection assessments}

Inattention and hyperactivity. Teachers of children $(\mathrm{N}=314)$ aged $7-11$ years completed the two subscales of the ACTeRS (Ullmann, at al., 1999) relating to attention and hyperactive behaviour. To classify children we used the cut-off values used in Study 1 and 
identified discrete groups with high inattention scores, high hyperactivity scores, and both high inattention and hyperactivity scores. A single control group with age-appropriate hyperactivity and attention scores were selected. Of the 64 children who obtained high scores on either the inattention and/or hyperactivity subscale, we selected three 'experimental' groups (each $\mathrm{N}=16$ ) matched to the control group $(\mathrm{N}=16)$ for chronological age, receptive vocabulary, and non-verbal IQ (see Table 5).

Non-verbal ability. Non-verbal reasoning ability was assessed with the MAT-SF (Naglieri, 1985), as before.

Receptive vocabulary. A group-administered version of the BPVS-II (Dunn, Dunn, Whetton \& Burley, 1997; see Stanovich \& Cunningham, 1992, for a similar modification) provided an estimate of receptive vocabulary. The test comprised one practice item and 50 test words. The experimenter read out the word and the child ticked the corresponding picture in their individual booklet. One point was awarded for each correct answer. Cronbach's alpha for this modified assessment was adequate, $\alpha=.73$.

\section{Reading and listening skills}

Word reading in context. The number of word reading errors made when reading the Form 1 stories from the NARA-II was recorded.

Single word reading. Children completed the single word reading test of the British Ability Scales - Second Edition (BAS-II: Elliott, Smith, \& McCulloch, 1996).

Reading and listening comprehension. A modified version of the NARA-II (Neale, 1997) was used to assess reading and listening comprehension. In the reading comprehension condition, children read the practice passage for Form 1, followed by stories 1-5. Unlike the standard administration, word reading errors were not corrected. In the 
assessment of listening comprehension, the experimenter read out the practice passage for Form 2, followed by stories 1-5. The comprehension questions were asked after each story. There were 4 questions for story 1 and 8 questions for all other stories. All children were given all of the stories. The NARA-II does not categorise passages as grade appropriate. In the standard administration of the task, the assessment starts with passage one for beginner readers, and passage two or three for 8- to 9-year-olds and over 10s respectively, although a word reading accuracy basal must be established if doing so. Testing is discontinued when the child has made a prescribed number of word reading errors on a given story. Thus, the administration procedure in this study differed from that typically used. All children, however, coped well with the task. Cronbach's alpha for our modified listening task was good, $\alpha=.84$.

\section{Results and summary}

Means and standard deviations of the reading and listening measures for Study 2 are reported in Table 6.

Table 6 around here

\section{Word reading}

The BAS-II single word reading total (raw) scores and the total errors when reading in context were analysed in two separate one-way ANOVAs: $F(3,60)=13.34, p<.001, F(3,60)$ $=9.75, p<.001$. Tukey posthoc comparisons (alpha $=.05$ ) were used to identify group differences. The pattern was the same for both measures: the poor attention and combined at-risk groups did not differ significantly from each other, but their performance was significantly lower than that of the high hyperactivity and control groups, indicating a word reading problem. In contrast, the children at risk of hyperactivity did not differ significantly 
in performance from the controls, indicating that this group did not have word reading difficulties.

\section{Reading and listening comprehension}

The sum total correct for stories 1 to 5 was the dependent variable in a repeatedmeasures analysis of variance with group (high hyperactivity, poor attention, combined, controls) as a between-subjects factor and modality (reading, listening) as the withinsubjects factor. There were main effects of group, $F(3,60)=10.88, p<.001, \eta_{p}{ }^{2}=.35$, modality, $F(1,60)=11.41, p<.001, \eta_{\mathrm{p}}{ }^{2}=.16$, and a significant interaction between the two, $F(3,60)=3.25, p<.05, \eta_{p}{ }^{2}=.14$. Simple effects analysis to examine the effect of modality revealed higher scores for reading than for listening comprehension for the high hyperactivity group, $F(1,15)=12.59, p<.01$, and the combined group, $F(1,15)=9.39, p<$ .01 , but the difference in scores for the poor attention group did not reach statistical significance, $F(1,15)=2.37, p=.15$. The difference was in the opposite direction for the control group, but was not significant, $F(1,15)=<1.0$, ns.

Table 6 around here

\section{Additional analyses to control for differences in word reading ability}

An additional ANOVA was performed on reading and listening comprehension scores, adjusted to take differences in word reading ability into account. A cut-off reading comprehension story was determined for each child based on the number of word reading errors they made: stories on which more than 12 word reading errors were made were not included in the analysis. This error level is the point at which the assessor may choose to discontinue testing, according to the manual. If a reading comprehension passage was removed due to a child exceeding this error limit, the parallel listening comprehension 
passage was also removed from the analysis, to enable a comparison of comprehension between the two modalities. The proportion correct score for the comprehension questions was calculated for both. These values were subjected to an arcsin transformation and treated as the dependent variable in an ANOVA with group and modality as factors. The adjusted scores are depicted in Figure 1.

\section{FIGURE 1 AROUND HERE}

In contrast to the analysis of unadjusted scores, there was not a significant effect of group, $F<1.0$, but there was a significant effect of modality, $F(1,60)=9.24, p<.01, \eta_{\mathrm{p}}{ }^{2}=.13$, and a significant interaction between group and modality, $F(3,60)=3.11, p<.05, \eta_{p}{ }^{2}=.13$, as before. Simple effects analysis to examine the effect of modality showed the same pattern as that found in the analysis of non-adjusted scores. There were significantly higher scores for reading than listening comprehension for the high hyperactivity group, $F(1,15)=15.90$, $p<.001$, and the combined group, $F(1,15)=14.82, p<.001$, but not for the poor attention group nor control groups, $F s<1.0$.

Our findings suggest that the subtypes of ADHD may have different literacy profiles. All groups experienced poor listening comprehension, relative to controls. However, the reading comprehension difficulties of children with poor attention (either alone or together with elevated levels of hyperactivity) were associated with weak word reading skills, in contrast to children with only high levels of hyperactivity who appeared to experience specific listening comprehension problems, with no evidence of word reading or reading comprehension difficulties relative to controls.

\section{General Discussion}


In line with previous research, we found that word reading difficulties were associated with poor attention. This was apparent in both studies, where weak word reading was found for children who fit the profile either of the inattentive or combined subtype and were, therefore, at risk of ADHD. Extending previous knowledge (Bauermeister, et al., 2005; Lamminmaki, Ahonen, Narhi, \& Lyytinen, 1995), we demonstrated that the reading comprehension difficulties associated with poor attention are partially mediated by weaknesses at the word level. Thus, the reading comprehension of children with poor attention can be limited, in part, because of their inefficient or inaccurate word decoding skills (Perfetti, 1985). Whether these word reading difficulties result from attention weaknesses or are comorbid is a theoretical issue that is outside the scope of the current work, although there is increasing evidence for the latter (Willcutt \& Pennington, 2000). In contrast to the inattentive and combined at-risk groups, the hyperactive at-risk group did not show any evidence of word reading difficulties nor of reading comprehension difficulties. Children at risk of hyperactivity do not, therefore, appear to be at risk of reading difficulties. For diagnostic purposes, this research demonstrates the need to assess both reading and listening comprehension, in addition to word reading ability, to determine the skills that should be the target of intervention. Clearly, one implication is that literacy intervention for children with poor attention should focus on support for word reading. In contrast to the control group, all of the at-risk subtypes in Study 2 had poorer listening comprehension than reading comprehension for matched stories. The relatively good reading comprehension of children with either poor attention and/or high ratings of hyperactivity is at first, surprising, because the memory and executive skills associated with reading comprehension (Cain, 2006; de Beni \& Palladino, 2000) are impaired in children 
with ADHD (Barkley, 1997; Gathercole et al., 2008) for evidence of the relation between poor attention, memory, and executive skills in non-diagnosed populations).

Our unique comparison between reading and listening comprehension provides an insight into the listening-reading comprehension difference. It has been suggested that reading comprehension may be good relative to listening comprehension in populations with poor attention and/or hyperactivity because visual presentation of text allows the comprehender to review and re-read when miscomprehensions arise, whereas listening does not provide such opportunities (Aaron, et al., 2002). However, our read aloud task was not optimal for such strategic reading. An alternative explanation is that the advantage for reading comprehension in this study arose because visually presented text helps the reader to focus attention and minimises distractibility. Indeed, children read aloud in our task, which has been shown to benefit groups diagnosed with ADHD (Ghelani et al., 2004). Another possibility for the reading comprehension advantage is that listening comprehension may be compromised because the listener cannot control the rate of delivery. In support of this explanation, recent work has found that children and adolescents with $A D H D$ require longer than non-diagnosed children to process complex sentences (Wassenberg et al., 2010). Future studies are needed to test between these alternatives specifically with children diagnosed with ADHD and, in addition, to understand why the children with at risk of hyperactivity had particular difficulties with listening comprehension.

The control for vocabulary skills in Study 2 by matching groups for vocabulary level enabled us to demonstrate a direct link between the symptoms of ADHD and text-level comprehension. In Study 2, all of our at-risk groups had poorer listening comprehension than reading comprehension and also poor listening comprehension than our controls when 
assessed on the same story set. The difference did not approach significance for the poor attention group, although we note that this is a small sample and the finding requires replication.

It seems unlikely that, in this sample, listening comprehension difficulties arose because of poor word comprehension, because the receptive vocabulary scores did not differ across groups in this study (see also Bental \& Tirosh, 2007). Other work has also shown a stronger relation between ADHD and complex measures of language comprehension, such as inference and integration, than lower-level phonological processing or verbal skills (Berthiaume, Lorch, \& Milich, 2010; Flory et al., 2006). Inference and integration are related to working memory (Cain, Oakhill, \& Lemmon, 2004; Cain, Oakhill, \& Bryant, 2004), which is often impaired in children with ADHD (Alloway, Gathercole, \& Elliott, 2010; Palladino, 2006) providing one possible explanation for the poor comprehension associated with ADHD. Research in another area of language comprehension - pragmatic skills - finds that performance is influenced by one of the symptoms of ADHD: hyperactivity ratings (Geurts \& Embrechts, 2008). Clearly, future work is needed to identify the precise relations between comprehension, inattention, and hyperactivity and the source of comprehension difficulties associated with these symptoms of ADHD.

It should be noted that the children in this study had not received a clinical diagnosis of ADHD and, therefore, the findings cannot be generalised to clinical populations. The teacher ratings indicated that these children were at risk of ADHD. These findings strongly suggest that children with diagnosed attention difficulties are at risk of poor word reading, that children diagnosed with hyperactivity are at risk of poor listening comprehension, and that children with both symptoms may experience difficulties with both components of 
reading comprehension. The sample size in this research is small, thus, replication of these findings with larger samples is required. Future work should also compare listening and reading comprehension in clinical samples to assess how presentation modality influences understanding and should also investigate performance in relation to independent assessments of attention and executive skills.

In summary, we have demonstrated a relation between text comprehension and the symptoms of ADHD over and above nonverbal skills and vocabulary. The combined findings suggest that any reading comprehension difficulties associated with poor attention are partly mediated by weak word reading. In contrast to reading comprehension, listening comprehension appears to be particularly vulnerable in children at risk of ADHD and, in particular, those children with high ratings for hyperactivity. 


\section{References}

Aaron, P. G., Joshi, R. M., Palmer, H., Smith, N., \& Kirby, E. (2002). Separating genuine cases of reading disability from reading deficits caused by predominantly inattentive ADHD behaviour. Journal of Learning Disabilities, 35, 425-435.

Adams, J. W., \& Snowling, M. J. (2001). Executive function and reading impairments in children reported by their teachers as 'hyperactive'. British Journal of Developmental Psychology, 19, 293-306.

Alloway, T. P., Gathercole, S. E., \& Elliott, J. (2010). Examining the link between working memory behaviour and academic attainment in children with ADHD. Developmental Medicine and Child Neurology, 52, 632-636.

Aro, T., Ahonen, T., Tolvanen, A., Lyytinen, H., \& Todd de Barra, H. (1999). Contribution of ADHD characteristics to the academic treatment outcome of children with learning difficulties. Developmental Neuropsychology, 15, 291-305.

American Psychological Association, (1994). Diagnostic and statistical manual of mental disorders (4 ed.). Washington DC: APA.

Barkley, R. A. (1997). Behavioural inhibition, sustained attention, and executive functioning: Constructing a unified theory of ADHD. Psychological Bulletin, 121, 65-94.

Baron, R. M., \& Kenny, D. A. (1986). The moderator-mediator variable distinction in social psychological research - conceptual, strategic, and statistical considerations. Journal of Personality and Social Psychology, 51, 1173-1182.

Bauermeister, J. J., Matos, M., Reina, G., Salas, C. C., Martinez, J. V., Cumba, E., et al. (2005). Comparison of the DSM-IV combined and inattentive types of ADHD in a school- 
based sample of Latino/Hispanic children. Journal of Child Psychology and Psychiatry, 46(2), 166-179.

Bental, B., \& Tirosh, E. (2007). The relationship between attention, executive functions and reading domain abilities in attention deficit hyperactivity disorder and reading disorder: A comparative study. Journal of Child Psychology and Psychiatry, 48, 455463.

Berthiaume, K. S., Lorch, E. P., \& Milich, R. (2010). Getting clued in: Inferential processing and comprehension monitoring in boys with ADHD. Journal of Attention Disorders, $14,31-42$.

Bignell, S., \& Cain, K. (2007). Pragmatic aspects of communication and language comprehension in groups of children differentiated by teacher ratings of inattention and hyperactivity. British Journal of Developmental Psychology, 25, 499-512.

Brock, S. E., \& Knapp, P. K. (1996). Reading comprehension abilities of children wtih Attention-Deficit/Hyperactivity Disorder. Journal of Attention Disorders, 1, 173-185.

Cain, K. (2006). Individual differences in children's memory and reading comprehension: an investigation of semantic and inhibitory deficits. Memory, 14, 553-569.

Cain, K., \& Oakhill, J. (2006). Profiles of children with specific reading comprehension difficulties. British Journal of Educational Psychology, 76, 683-696.

Cain, K., Oakhill, J., \& Lemmon, K. (2004). Individual differences in the inference of word meanings from context: the influence of reading comprehension, vocabulary knowledge, and memory capacity. Journal of Educational Psychology, 96, 671-681. 
Cain, K., Oakhill, J. V., \& Bryant, P. E. (2004). Children's reading comprehension ability: Concurrent prediction by working memory, verbal ability, and component skills. Journal of Educational Psychology, 96, 671-681.

Carroll, J. M., Maughan, B., Goodman, R., \& Meltzer, H. (2005). Literacy difficulties and psychiatric disorders: evidence for comorbidity. Journal of Child Psychology and Psychiatry, 46, 524-532.

Cohen, J., \& Cohen, P. (1983). Applied Multiple Regression/Correlation Analysis for the Behavioral Sciences (2 ed.). Hillsdale, New Jersey: Lawrence Erlbaum Associates. de Beni, R., \& Palladino, P. (2000). Intrusion errors in working memory tasks: are they related to reading comprehension ability? Learning and Individual Differences, 12, 131-143.

de Jong, P. F., \& van der Leij, A. (2002). Effects of phonological abilities and linguistic comprehension on the development of reading. Scientific Studies of Reading, 6, 5177.

Dunn, L. M., Dunn, L. M., Whetton, C., \& Burley, J. (1997). British Picture Vocabulary Scale (2 ed.): GL Assessment.

Elliott, C. D., Smith, P., \& McCulloch, K. (1996). British Ability Scales: Second Edition. Windsor: NFER: Nelson.

Flory, K., Milich, R., Lorch, E. P., Hayden, A. N., Strange, C., \& Welsh, R. (2006). Online story comprehension among children with ADHD: Which core deficits are involved? Journal of Abnormal Child Psychology, 34, 853-865. 
Frazier, T. W., Youngstrom, E. A., Glutting, J. J., \& Watkins, M. W. (2007). ADHD and achievement: meta-analysis of the child, adolescent, and adult literatures and a concomitant study with college students. Journal of Learning Disabilities, 40, 49-65.

Gathercole, S. E., Alloway, T. P., Kirkwood, H. J., Elliott, J. G., Holmes, J., \& Hilton, K. A. (2008). Attentional and executive function behaviours in children wtih poor working memory. Learning and Individual Differences, 18, 214-223.

Geurts, H. M., \& Embrechts, M. (2008). Language profiles in ASD, SLI, and ADHD. Journal of Autism and Developmental Disorders, 38, 1931-1943.

Ghelani, K., Sidhu, R., Jain, U., \& Tannock, R. (2004). Reading comprehension and reading related ablities in adolescents wtih reading disabilities and attentiondeficit/hyperactivity disorder. Dyslexia, 10, 364-384.

Gough, P. B., \& Tunmer, W. E. (1986). Decoding, reading and reading disability. Remedial and Special Education, 7, 6-10.

Hinshaw, S. P. (1992). Externalising behaviour problems and academic achievement in childhood and adolescence: Causal relationships and underlying mechanisms. Psychological Bulletin, 111, 127-155.

Hoover, W. A., \& Gough, P. B. (1990). The simple view of reading. Reading and Writing, 2, 127-160.

Keenan, J. M., Betjemann, R. S., Wadsworth, S. J., DeFries, J. C., \& Olson, R. K. (2006). Genetic and environmental influences on reading and listening comprehension. Journal of Research in Reading, 29, 75-91.

Kendeou, P., Savage, R., \& van den Broek, P. (2009). Revisiting the simple view of reading. British Journal of Educational Psychology, 79, 353-370. 
Kintsch, W. (1998). Comprehension: A paradigm for cognition. New York, NY: Cambridge University Press.

Lamminmäki, T., Ahonen, T., Närhi, V., Lyytinen, H., \& de Barra, H. T. (1995). Attention deficit hyperactivity disorder subtypes: Are there differences in academic problems? Developmental Neuropsychology, 11, 297-310.

Lombardino, L. J., Riccio, C. A., Hynd, G. W., \& Pinheiro, S. B. (1997). Linguistic deficits in children with reading disabilities. American Journal of Speech-Language Pathology, $6,71-78$.

Lorch, E. P., Diener, M. B., Sanchez, R. P., Milich, R., Welsh, R., \& van den Broek, P. (1999). The effects of story structure on the recall of stories in children with attention deficit hyperactivity disorder. Journal of Educational Psychology, 91, 273-283.

McGee, R., Prior, M., Williams, S., Smart, D., \& Sanson, A. (2002). The long-term significance of teacher-rated hyperactivity and reading ability in childhood: Findings from two longitudinal studies. Journal of Child Psychology and Psychiatry, 43, 1004-1016.

McGee, R., Williams, S., Share, D. L., Anderson, J. W., \& Silva, P. A. (1986). The relationship between specific reading retardation, general reading backwardness and bahavioural problems in a large sample of Dunedin boys: A longitudinal study from five to eleven years. Journal of Child Psychology and Psychiatry, 27, 597-610.

Mclnnes, A., Humphries, T., Hogg-Johnson, S., \& Tannock, R. (2003). Listening comprehension and working memory are impaired in Attention-Deficit Hyperactivity Disorder irrespective of language impairment. Journal of Abnormal Child Psychology, 31, 427-443. 
Miller, G. A., \& Chapman, J. P. (2001). Misunderstanding analysis of covariance. Journal of Abnormal Child Psychology, 110, 40-48.

Muter, V., Hulme, C., Snowling, M., \& Stevenson, J. (2004). Phonemes, rimes, vocabulary and grammatical skills as foundations of early reading development: evidence from a longitudinal study. Developmental Psychology, 40, 665-681.

Naglieri, J. A. (1985). The Matrix Analogies Test: Short Form. New York: The Psychological Corporation.

Nation, K., \& Snowling, M. (2004). Beyond phonological skills: broader language skills contribute to the development of reading. Journal of Research in Reading, 27, 342356.

Neale, M. D. (1997). The Neale Analysis of Reading Ability - Revised (NARA-II). Windsor: NFER-Nelson.

Oakhill, J. V., \& Cain, K. (2012). The precursors of reading comprehension and word reading in young readers: Evidence from a four-year longitudinal study. Scientific Studies of Reading, 16, 91-121.

Oakhill, J. V., Cain, K., \& Bryant, P. E. (2003). The dissociation of word reading and text comprehension: Evidence from component skills. Language and Cognitive Processes, $18,443-468$.

Palladino, P. (2006). The role of interference control in working memory: A study of children at risk of ADHD. The Quarterly Journal of Experimental Psychology, 59, 2047-2055.

Pennington, B. F., \& Ozonoff, S. (1996). Executive functions and developmental psychopathology. Journal of Child Psychology and Psychiatry, 37, 51-87.

Perfetti, C. A. (1985). Reading Ability. New York: Oxford University Press. 
Preacher, K. J., \& Hayes, A. F. (2008). Asymptotic and resampling strategies for assessing and comparing indirect effects in multiple mediation models. Behavior Research Methods, 40, 879-891.

Shaywitz, B. A., Fletcher, J. M., \& Shaywitz, S. E. (1995). Defining and classifying learning disabilities and attention-deficit/hyperactivity disorder. Journal of Child Neurology, 10, S50-57.

Stanovich, K. E., \& Cunningham, A. E. (1992). Studying the consequences of literacy within a literate society: The cognitive correlates of print exposure. Memory and Cognition, 20, 51-68.

Tirosh, E., \& Cohen, A. (1998). Language deficit with attention-deficit disorder: A prevalent comorbidity. Journal of Child Neurology, 13, 493-497.

Ullmann, R. K., Sleator, E. K., \& Sprague, R. L. (1999). The ADD-H Comprehensive Teacher's Rating Scale (ACTeRS) (2nd ed.). Champaign, IL: MetriTech Inc.

Wassenberg, R., Hendriksen, J. G. M., Hurks, P. P. M., Feron, F. J. M., Vles, J. S. H., \& Jolles, J. (2010). Speed of language comprehension is impaired in ADHD. Journal of Attention Disorders, 13, 374-385.

Wilding, J. M., Munir, F., \& Cornish, K. (2001). The nature of attentional differences between groups of children differentiated by teacher ratings of attention and hyperactivity. British Journal of Psychology, 92, 357-371.

Willcutt, E., \& Pennington, B. F. (2000). Comorbidity of reading disability and attentiondeficit /hyperactivity disorder. Journal of Learning Disabilities, 33, 179-191.

Willcutt, E., Pennington, B. F., Olson, R. K., Chhabildas, N., \& Hulslander, J. (2005). Neuropsychological analyses of comorbidity between reading disability and 
attention deficit hyperactivity disorder: in search of a common deficit.

Developmental Neuropsychology, 27, 35-78. 